University of Warwick institutional repository: http://go.warwick.ac.uk/wrap

This paper is made available online in accordance with publisher policies. Please scroll down to view the document itself. Please refer to the repository record for this item and our policy information available from the repository home page for further information.

To see the final version of this paper please visit the publisher's website. Access to the published version may require a subscription.

Author(s): Cassam, Q.

Article Title: Knowledge, Perception and Analysis

Year of publication: 2008

Link to published article : http://www.sajp.za.net/

Publisher statement: Cassam, Q. (2008). Knowledge, perception and analysis. South African Journal of Philosophy. 27(3), pp. 36-48. 


\title{
Knowledge, Perception and Analysis
}

\author{
Quassim Cassam
}

\section{Introduction.}

A point that Strawson often emphasized in his writings is that the concepts of knowledge and perception are closely linked. For example, the idea of such a link does important work in his exposition and defence of a causal analysis of perception. ${ }^{1}$ According to this analysis a material object $\mathrm{M}$ is perceived by a subject $\mathrm{S}$ only if $\mathrm{M}$ causes an experience in S. Why should this be? One reason, according to Strawson, is that such a causal requirement on perception is implied by perception's knowledge-giving role. ${ }^{2}$ This is one sense in which, in the words of Strawson's last book, 'we could not explain all the features of the concept of sense perception without reference to the concept of knowledge' (1992: 19).

I'm not going to be concerned here with the merits or otherwise of a causal analysis of perception or with the proposal that such an analysis is implied by the knowledge-giving role of perception. Instead, I want to focus on the supposed knowledge-giving role of perception. How should the idea that perception has such a role be understood? Suppose we say that it is somehow built into the concept of perception that perceiving an object is a way of acquiring knowledge of the object. Yet, as Snowdon points out in a helpful discussion of Strawson's views, 'it is not a necessary truth that if S sees $\mathrm{M}$ then $\mathrm{S}$ can gain knowledge of M' (1998: 301). For example, S may not realize that he is seeing $M$ or may be seeing $M$ in a deceptive way. One challenge in this area, therefore, is to come up with a viable account of the knowledge-giving role of perception.

\footnotetext{
${ }^{1}$ See Strawson 2008.

2 Snowdon mentions the 'knowledge-giving role of perception' in his Foreword to the 2008 edition of Freedom and Resentment. My account of Strawson's argument is indebted to Snowdon's Foreword.
} 
In the passage in which Strawson suggests that we can't explain all the features of the concept of perception without reference to the concept of knowledge he also speculates that 'we could not fully elucidate the concept of knowledge without reference to the concept of sense perception' (1992: 19). The possibility that the concepts of knowledge and perception hang together in this way is used by Strawson to make a case for his preferred non-reductive model of conceptual analysis. To give a reductive analysis of a concept is to analyse it in more basic terms. Specifically, the idea is that some concepts 'can be reduced to, or wholly explained in terms of, some others which are felt to be more perspicuous' (1995: 16). The causal analysis of perception might be thought of as reductive in this sense but Strawson insists that in general he is 'extremely sceptical' (1995: 16) about reductive analyses of concepts. The problem is that:

The philosophically interesting or important concepts tend to remain obstinately irreducible, in the sense that they cannot be defined away, without remainder or circularity, in terms of other concepts (1995: 16).

The recommended alternative is to think of individual concepts as belonging to an elaborate network of concepts such that the function of each concept could 'from the philosophical point of view, be properly understood only by grasping its connections with the others, its place in the system' (1992: 19). Circularity needn't be a problem for someone who sees things in this way, and this is the context in which Strawson makes the point that neither the concept of knowledge nor that of perception can be fully elucidated without reference to the other.

Should we accept that the concept of knowledge can't be fully elucidated without reference to the concept of sense perception? Obviously, a lot depends on the word 'fully'. 
Standard reductive accounts of the concept of knowledge try to analyse it terms of concepts like truth, belief, justification and reliability. If knowledge is justified true belief, or true belief caused by a generally reliable process, then perception can certainly be a source of knowledge. After all, perception can give one justified true beliefs about the world beyond and is a generally reliable process. So if this is all that Strawson means when he says that the concept of knowledge can't be fully elucidated without reference to the concept of perception then there is nothing especially novel or radical about his suggestion. Our most fundamental understanding of the concept of knowledge would be in terms of concepts like truth, belief, justification and reliability, and we can then go on, on this basis, to identify specific sources of knowledge such as perception. The status of perception as a source of knowledge would be, to this extent and in this sense, derivative rather than primitive.

There is, however, a far more radical way of understanding the connection between perception and knowledge. The idea would be that knowledge is to be explicated, in the first instance, by reference to its sources. ${ }^{3}$ In other words, we understand what knowledge is by understanding how we get it or how it comes to be. Clearly, there are many different ways in which knowledge comes to be but an absolutely basic source of knowledge is perception. So we now have the proposal that 'our fundamental understanding of knowledge is as what is yielded by perception in certain circumstances' (Snowdon 1998: 301). ${ }^{4}$ If this is right then there would be a very clear sense in which we could not elucidate the concept of knowledge without reference to the concept of perception. There would still be more general things to be said about what it is to know but there would no longer be any question of basing the connection between knowledge and perception on a prior reductive

\footnotetext{
${ }^{3}$ See the opening of Audi 2002 for a suggestion along these lines.

${ }^{4}$ This is not a view that Snowdon himself endorses.
} 
analysis of the concept of knowledge. The connection between knowledge and perception would be primitive rather than derivative.

These claims about knowledge, perception and analysis are all controversial so I'm going to proceed as follows: in part 2, I will say more about the knowledge-giving role of perception. My main suggestion will be that the best way of understanding this role would be in explanatory terms. In other words, reference to what subjects can perceive often has an important part to play in explaining how they know. In part 3, I will focus on Strawson's account of conceptual analysis in Analysis and Metaphysics and on the suggestion that our fundamental understanding of knowledge is as what is yielded by perception. I will argue that there is something right about this suggestion even though it faces some formidable challenges. Finally, in part 4, I will discuss Strawson's philosophical methodology in the light of more recent developments in the philosophy of philosophy.

\section{Perception and Knowledge.}

Suppose I see that the building in front of me is a barn. It would seem to follow that I know that the building in front of me is a barn. A familiar thought is that this follows because 'S sees that $\mathrm{P}$ ' actually entails 'S knows that $\mathrm{P}$ '. ${ }^{5}$ More generally, given that seeing that $\mathrm{P}$ is not the only way of perceiving that $\mathrm{P}$, one might think that ' $\mathrm{S}$ perceives that $\mathrm{P}$ ' entails ' $\mathrm{S}$ knows that $\mathrm{P}$ '. If this is right then the sense in which perception is knowledgegiving is that it is knowledge-entailing. Anyone who sees or perceives that $\mathrm{P}$ thereby knows that $\mathrm{P}$ because, as Peacocke puts it, 'perceiving that $\mathrm{P}$ is a form of knowing that $\mathrm{P}$ ' (2005: 229).

If perceiving that $\mathrm{P}$ is a form of knowing that $\mathrm{P}$ then it is easy to see why we could not explain all the features of the concept of perception without reference to the concept of

\footnotetext{
${ }^{5}$ See Dretske 1969, Unger 1975 and Williamson 2000 for a defence of this claim.
} 
knowledge. ${ }^{6}$ But now consider a case in which, instead of seeing that the building in front of me is a barn, I simply see the barn. From 'S sees a barn' or ' $\mathrm{S}$ can see a barn', it does not follow that $\mathrm{S}$ knows that there is a barn there. ${ }^{7}$ This kind of seeing or perceiving is not knowledge-entailing. So either it is false that perception always has a knowledge-giving role or, as I want to argue, its having such a role need not consist in its being knowledgeentailing.

How might it happen that a person $\mathrm{S}$ sees a barn in front of him but doesn't know that there is a barn in front of him? Here are three cases:

(a) S sees a barn but doesn't know what a barn is - he lacks the concept barn. This needn't prevent him from seeing the barn but he can't be said to know that there is a barn in front of him if he doesn't know what a barn is.

(b) S sees a barn, has the concept barn but for some reason doesn't recognize what he sees as a barn. Perhaps he mistakenly believes that he is in fake barn country and that what he is looking at is a fake barn that looks like a barn from a distance. ${ }^{8}$ If he doesn't recognize what he sees as a barn then he doesn't know that it's a barn even if it is a barn.

(c) S sees what is in fact a barn, he has the concept barn, and believes that what he is looking at is a barn but, unknown to $\mathrm{S}$, he is actually in fake barn country. He can't tell the difference between a real and a fake barn and so he doesn't know that there is a barn in front of him. By the same

\footnotetext{
${ }^{6} \mathrm{I}$ take it that if perceiving is a form of knowing then this is built into the concept of perception.

${ }^{7}$ Notice that 'S can see a barn' doesn't mean ' $\mathrm{S}$ is able to see a barn'.

${ }^{8}$ Fake barn country contains one or two genuine barns and lots of fake barns that look a lot like barns from a distance. The example is associated with Alvin Goldman, who attributes it to Carl Ginet. See Goldman 1992.
} 
token, he doesn't see that there is a barn in front of him in these circumstances. Yet he still sees a barn. The correct answer to the question 'What can S see?' is 'A barn'.

These cases all put pressure on the idea that there is a necessary link between knowledge and perception. They do not show that perception doesn't have a knowledge-giving role but they raise a question about how this role is to be understood.

The distinction between seeing a barn and seeing that there is a barn nearby maps on to Dretske's distinction between non-epistemic or 'simple' seeing and epistemic seeing. ${ }^{9}$ In epistemic seeing one sees that something is the case. The main characteristics of this kind of seeing are that it is propositional, factive, and has epistemic implications: it implies something about what the perceiver knows and about his conceptual resources. If $\mathrm{S}$ sees that there is a barn nearby then there is a barn nearby. If S sees that there is a barn nearby then he must have the concept barn. Finally, if $\mathrm{S}$ sees that there is a barn nearby then he knows that there is a barn nearby. Simple seeing, in contrast, is non-propositional, nonfactive and lacks the epistemic implications of epistemic seeing. Simple seeing is 'the seeing of objects and things - not facts about these things' (Dretske 2000: 98), and so is not constrained by one's conceptual resources. Even babies and animals that don't know what barns are can still see barns.

If simple seeing is not knowledge-entailing and so not a form of knowing in what sense can it still have a knowledge-giving role? The best way of answering this question is to think about the role of this kind of seeing in explaining how we know some of the things we know about the world around us. In spelling out this idea it is helpful to keep in mind that if it is correct to describe a person $\mathrm{S}$ as knowing that $\mathrm{P}$ then there must be an answer to

\footnotetext{
${ }^{9}$ See Dretske 1969 and 2000.
} 
the question 'How does $\mathrm{S}$ know that $\mathrm{P} ?{ }^{\prime}{ }^{10}$ The claim is not that $\mathrm{S}$ must know the answer to this question but that there must be an answer. Furthermore, a satisfying answer will be one that explains how $\mathrm{S}$ knows that $\mathrm{P}$. So the next question is this: what would it be to explain S's knowledge, say in the case in which what $\mathrm{S}$ is said to know is that there is a barn in the vicinity?

A compelling thought is that, as Shoemaker puts it, "faced with the question of how someone knows something, the most satisfying answer we can be given is "She saw it", (1996: 201). Seeing is, on this account, the 'paradigmatic explanation of knowing' (ibid.). This is not to say that perceptual explanations are always acceptable. If it is too dark for $\mathrm{S}$ to see anything or if S is blind then 'He can see it' clearly won't be a good answer to 'How does S know that there is a barn nearby?'. However, this doesn't affect Shoemaker's point. For seeing to be the paradigmatic explanation of knowing it is not necessary that 'She saw it' is in all circumstances a good answer to the explanatory question.

What kind of seeing is the paradigmatic explanation of knowing? ${ }^{11}$ Sometimes we explain how $\mathrm{S}$ knows that $\mathrm{P}$ by reference to the fact that $\mathrm{S}$ can see that $\mathrm{P}$. Such explanations in terms of epistemic seeing might seem good because they are knowledge-entailing and so don't leave it open that $\mathrm{S}$ doesn't know that $\mathrm{P} .{ }^{12}$ One might dispute the claim that $\mathrm{S}$ can see that $\mathrm{P}$ but once one agrees that $\mathrm{S}$ can see that $\mathrm{P}$ then that is the end of the matter: $\mathrm{S}$ knows that $\mathrm{P}$ and it is clear how he knows that $\mathrm{P}$, unless he already knew that $\mathrm{P}$ or knows it in more than one way. In contrast, as we have seen, the mere fact that $S$ sees a barn nearby does not settle the question whether he knows that there is a barn nearby. In that case, aren't we forced to admit either that ' $\mathrm{S}$ can see it' is not a satisfactory answer to the

\footnotetext{
${ }^{10}$ I defend this claim in Cassam 2007.

${ }^{11}$ Shoemaker's formulation leaves this question open.

${ }^{12}$ In Cassam 2007 I refer to this as the 'finality' of (some) perceptual explanations.
} 
question 'How does S know that there is a barn nearby?' or that it is satisfactory only to the extent that it is shorthand for an explanation in terms of epistemic seeing? How can 'He can see it' be a good explanation of S's knowledge if it leaves it open that S doesn't know that there is a barn nearby?

The question that this raises is whether good epistemic explanations have to be knowledge-entailing. To see why not consider this example: S knows that Quine was born in Akron, and we want to know how he knows. So we ask him. His answer is that he read that Quine was born in Akron in Quine's autobiography. Is this a good answer? That is, does it tell us how $\mathrm{S}$ knows that Quine was born in Akron (assuming that $\mathrm{S}$ is being truthful about his reading habits)? Yes. Is it a knowledge-entailing explanation? No. 'S read that P' does not entail 'S knows that P. It can't possibly entail this because it doesn't even entail P. In this sense, the proposed explanation leaves it open that $\mathrm{S}$ does not know that $\mathrm{P}$. Even if $\mathrm{P}$ is true one can still wonder whether $\mathrm{S}$ knows that $\mathrm{P}$ just because he read that $\mathrm{P}$. For example one might be reluctant to accept that S knows that Quine was born in Akron if S has ignored compelling but misleading evidence that Quine's autobiography is full of factual errors. But none of this means that S's explanation is not a good one in the absence of such defeaters. $^{13}$

There are many non-epistemological examples that make the same point about the nature of explanation. Suppose that $\mathrm{S}$ was in London this morning and is now in Paris. How did he get to Paris? He caught the Eurostar from London. This explains how S got to Paris

\footnotetext{
${ }^{13}$ It is also worth pointing out that there are many sentences of the form ' $\mathrm{S} \Phi \mathrm{s}$ that $\mathrm{P}$ ' that do entail ' $\mathrm{S}$ knows that $\mathrm{P}$ ' but that cannot be used to explained to explain how $\mathrm{S}$ knows that $\mathrm{P}$. For example, it is arguable that 'S regrets that $\mathrm{P}$ ' entails ' $\mathrm{S}$ knows that $\mathrm{P}$ ' (see Unger 1975) but ' $\mathrm{S}$ regrets that $\mathrm{P}$ ' is, in most circumstances, a deviant answer to 'How does $S$ know that P?'. The same point could be made about the relationship between 'S admits that $\mathrm{P}$ ' and ' $\mathrm{S}$ knows that $\mathrm{P}$ '. Admitting that $\mathrm{P}$ isn't usually a way of knowing that $\mathrm{P}$ (though one can perhaps imagine circumstances in which it might be).
} 
but, as seasoned travellers know only too well, 'S caught this morning's Eurostar from London' doesn't entail 'S is now in Paris'. Trains can break down. In explaining how S got to Paris by saying that he caught the Eurostar we are taking it for granted that none of the many things that could have gone wrong and prevented $S$ from reaching Paris by train did go wrong. There are many background conditions that need to be fulfilled for catching the Eurostar to be a way of getting from London to Paris. In explaining S's now being in Paris by reference to his having caught the Eurostar this morning we presuppose, but do not state, that these conditions have been fulfilled.

This is the key to understanding the barn case. The mere fact that an explanation of S's knowledge in terms of non-epistemic seeing is not knowledge-entailing does not make it a defective explanation. If that were the case we would also be forced to accept that S's explanation of his knowledge that Quine was born in Akron is defective but this is not something that we do or should accept. Of course, the two examples are different in another respect. In the Quine example, the proposed explanation is propositional even if it isn't factive. To say that $\mathrm{S}$ knows there is a barn nearby because he can see the barn is to explain his knowledge by reference to non-propositional seeing. Yet this is no reason to regard the explanation as defective. Seeing a barn nearby can provide one with the knowledge that there is a barn nearby as long as various background conditions are fulfilled. Some of these conditions are subjective, that is, conditions that the perceiver must fulfil. For example, he must know what a barn is. Other conditions are objective: for example, it mustn't be the case that he is in fake barn country. As long as we have no reason to suppose that these conditions are not fulfilled we should be happy to accept that someone who says 'I can see it' has satisfactorily explained how he knows there is a barn nearby. 
It seems, then, that simple seeing can, in the right circumstances have a knowledgeexplaining role, and this is enough to justify the claim that it can have a knowledge-giving role in such circumstances. Unlike epistemic seeing, simple seeing is only conditionally knowledge-giving but this doesn't mean that it isn't a potentially a pathway to knowledge. Where does this leave Strawson's suggestion that we could not explain all the features of the concept of perception without reference to the concept of knowledge? In good shape, it would seem. It is clear enough that we could not explain all the features of the concept of epistemic perception without reference to the concept of knowing because it is built into the idea of this kind of perceiving that it is a form of knowing. Simple seeing is not a form of knowing but someone who doesn't grasp that it can nevertheless be a route to knowledge is arguably someone who lacks a full understanding of this form of perception. To bring this out imagine the following dialogue:

Question: How do you know there is a barn over there?

Answer: I can see it.

Question: I know you can see it but how do you know that there is a barn over there?

Of course, there are circumstances in which the second question in this dialogue might be reasonable. Maybe the questioner thinks that the perceiver is in fake barn country. But if the questioner doesn't have anything like that in mind and asks his question simply because he cannot see what seeing the barn has got to do with knowing that there is barn over there then we would have to conclude that he doesn't know what seeing is. Perceiving does not always result in knowing but it is built into the concept of perception that it potentially a 
pathway to knowledge. That is why we could not explain all the features of the concept of perception without reference to the concept of knowledge. ${ }^{14}$

As a matter of fact, it isn't just the questioner's grasp of the concept of seeing that would be called into question by the above dialogue. One might also wonder how good a grasp he has of the concept of knowledge. For just as it is fundamental to our grasp of the concept of perception that we recognize it as a source of knowledge so one might think that it is fundamental to our grasp of the concept of knowledge that we think of it as something that perception can give us. This would be one way of understanding Strawson's suggestion that the concept of knowledge can't be fully elucidated without reference to the concept of sense perception. It is to this suggestion that I now turn.

\section{Knowledge and Perception.}

A familiar idea is that if we want to know what knowledge is then we need to start by analysing the concept of knowledge. On a reductive conception of analysis a successful analysis of this concept will be one that breaks it down into more basic concepts like truth, belief and justification. The sense in which these concepts are more basic is that they can themselves be analysed or explained without any reference to the concept of knowledge. And if concepts like truth, $\underline{\text { belief }}$ and justification are, in this sense, more basic than the concept of knowledge then they can be used to give non-circular necessary and sufficient conditions for knowing. Once we have come up with such conditions we can claim to have given a reductive analysis of the concept of knowledge and thereby to have answered the question 'What is knowledge?'.

Where does this leave specific sources of knowledge such as perception? Someone who thinks that knowledge is, say, justified true belief should, of course, be happy to agree

\footnotetext{
${ }^{14}$ The argument of this paragraph is heavily indebted to conversations with Paul Snowdon.
} 
that perception is a source of knowledge. His point is that that our fundamental understanding of the concept of knowledge is in terms of concepts like truth, belief and justification, and that this is what makes it intelligible that perception is a source of knowledge. Perception is a source of knowledge because it is a source of justified true beliefs about the world around us. But the fact that perception is a source of knowledge doesn't mean that the concept of knowledge can't be fully elucidated without reference to the concept of perception. The concept of knowledge has already been fully elucidated at the point at which we arrive at non-circular necessary and conditions for knowing.

On this account, the connection between knowledge and perception is derivative rather than primitive. What this means is that we understand how perception can be a source of knowledge only because we have a prior understanding of generic conditions for knowing, conditions such as truth, belief and justification. To characterize these conditions as generic is to make the point that there are many different ways in which they can be realized. Perceiving that $\mathrm{P}$ is a way of knowing that $\mathrm{P}$ in so far as it is a way of coming to have the justified true belief that $\mathrm{P}$ but one can also come to have the justified true belief that $\mathrm{P}$ in many other ways. Knowers don't have to be perceivers. It surely makes sense to suppose that a non-perceiving creature (God?) can know things, and this suggests that we should be sceptical about the idea, mentioned above, that our fundamental understanding of knowledge is as what perception gives us. Our fundamental understanding, one might think, is in terms of the more generic conditions on knowing that reductive analyses of the concept of knowledge try to identify.

As we have seen, Strawson is no fan of reductive conceptual analysis. In Analysis and Metaphysics he argues as follows against the reductive model of analysis: the general 
implication of the name 'analysis' seems to be that of 'the resolution of something complex into elements and the exhibition of the ways the elements are related in the complex' (1992: 17). Chemical analysis stops with chemical elements, physical analysis with physical elements, and so on. In each case 'we stop with items which are, from the point of view of the investigation in question, completely simple, the ultimate elements as regards that kind of analysis' (1992: 17). If this is how we think of conceptual analysis we should conclude that:

our task was to find ideas that were completely simple, that were free from internal conceptual complexity; and then to demonstrate how the more or less complex ideas that are of interest to philosophers could be assembled by a kind of logical or conceptual construction out of these simple elements (1992: 17).

Strawson rightly describes this project as implausible but he suggests that the associated 'dismantling' (1992: 19) model of analysis continues to exercise 'a certain influence on the philosophical mind' (1992: 18). Here is his evidence for this surprising suggestion:

When confronted with the task of giving a philosophical elucidation of some particular concept - say that of someone's knowing something to be the case or that of someone's perceiving some material object- we often attack it by trying to set out in general terms, both the conditions which must be satisfied if the concept is to be correctly applied and the conditions which are such that the concept must be correctly applicable if those conditions are satisfied. That is to say, in our jargon, we try to ascertain necessary and sufficient conditions for the correct application of the concept (1992: 18). 
As Strawson acknowledges someone who operates in this way needn't think that the object of the exercise is to include only absolutely simple concepts in specifying necessary and sufficient conditions for the correct application of the target concept. For example, those who analyse knowledge in terms of belief don't typically think that the concept of belief can't itself be analysed further. So why think that the dismantling model of analysis is doing any serious work here? Because those who try to ascertain necessary and sufficient conditions for the correct application of concepts like knowledge and perception almost always assume that the conditions they come up must be non-circular. But circularity is only a problem if

we are thinking in terms of that model of analysis which represents it as a kind of dismantling of a complex structure into simpler elements, a process which terminates only when you reach pieces which cannot be further dismantled; for this process has not even begun if one of the alleged pieces turns out to be, or to contain, the very concept, that was to be dismantled (1992: 19).

By the same token, once we abandon the dismantling model we are free to adopt Strawson's non-reductive 'network' model of analysis. This requires us to think of concepts as belonging to an elaborate network of concepts such that the function of each concept can only be understood by grasping its connections with the others. If this becomes our model, 'there will be no reason to be worried if, if the process of tracing connections from one point to another of the network, we find ourselves returning to, or passing through, our starting-point' (1992: 19).

How compelling is Strawson's objection to the reductive model of analysis? That depends on whether it is plausible that those who seek necessary and sufficient conditions 
for the application of concepts like knowledge only think that an acceptable analysis must be non-circular because they are in the grip of the dismantling model, which models all analysis on chemical analysis. This seems far-fetched. The usual worry about circularity is that analyses that suffer from this defect are somehow question-begging or unilluminating, perhaps in the sense that someone who does not already have the concept being analysed would be left none the wiser by the proposed analysis. Whatever the merits of this objection to circular analyses, it is not obvious that it can only be motivated by a commitment to the dismantling model. While this model might have been historically influential there is surely no intrinsic connection between it and the idea that circular analyses are unacceptable.

Fortunately, there are better objections to the project of analysing the concept of knowledge in more basic terms than the one that Strawson presses. For example, it might be argued that that the concept of knowledge is prior to, and more basic than, the concept of justified belief and so cannot be reductively analysed as justified true belief $+\mathrm{X} .{ }^{15}$ Timothy Williamson makes this point in Knowledge and its Limits, where he argues that only knowledge can justify belief. ${ }^{16}$ Another Williamsonian argument against the reductive project is inductive. Surely non-circular necessary and sufficient conditions for knowing would already have been discovered if they were discoverable? It might also be pointed out that few concepts have reductive analyses and that there is no reason to expect the concept of knowledge to be special in this regard.

This is not the place for a detailed assessment of these arguments, though it is worth pointing out that they are all, to varying degrees, controversial. ${ }^{17}$ For example, externalists who think that the justificational status of a belief is a function of the reliability of the

\footnotetext{
${ }^{15} \mathrm{The}$ ' $\mathrm{X}$ ' is needed to deal with Gettier cases.

${ }^{16}$ See, especially, chapter 9 of Williamson 2000.

${ }^{17}$ I discuss Williamson's arguments in Cassam, forthcoming.
} 
processes that caused it won't agree that only knowledge can justify belief. A belief can be caused by a highly reliable process without the believer knowing that this is so. Here we have a case in which a belief is justified alright but not by a proposition that the believer knows. To keep things simple, however, let us suppose that one or more of Williamson's arguments is successful and that they are all arguments of which Strawson could happily avail himself. ${ }^{18}$ The question that now arises is this: if we are not to explain what knowledge is by producing a standard reductive analysis of the concept of knowledge what is the alternative? Strawson talks about tracing the connections between different but interrelated concepts in a network of concepts but it is not clear how this is to be cashed out. The remarks on this topic in Analysis and Metaphysics are highly suggestive but also frustratingly metaphorical.

Here is one way of making Strawson's idea a bit more concrete: if a person knows that $\mathrm{P}$ then there must be a specific way in which he knows that $\mathrm{P} .{ }^{19} \mathrm{He}$ can't 'just know' without there being a way in which he knows. This connects with the point, made above, that if it is correct to describe a person $\mathrm{S}$ as knowing that $\mathrm{P}$ then there must be an answer to the question 'How does S know that P?'. This question is one to which knowers are always exposed because there must always be a way in which they know what they know and because it is the way that the question is after. ${ }^{20}$ So what would a good answer to 'How do

\footnotetext{
${ }^{18}$ Williamson's best argument, and the one in which I believe he has the greatest faith, is the inductive argument.

${ }^{19}$ For a defence of this claim see Williamson 2000 and Cassam 2007. My conception of 'ways of knowing' is, however, different from Williamson's. He conceives of knowledge as a determinable and specific ways of knowing as determinates of the determinable. So, for example, the sense in which seeing is a way of knowing is analogous to the sense in which being red is a way of being coloured. A way of knowing in my sense is more like a way of coming to know or, more accurately, the basis on which one knows. The idea that someone who asserts that $\mathrm{P}$ is directly exposed to the question 'How do you know?' is one that Austin emphasizes in his paper 'Other Minds' (Austin 1979).

${ }_{20}$ Actually, this is a bit of an oversimplification. As Austin points out there are many different ways of understanding and answering the question 'How do you know?'. Consider this dialogue: 'There is a bittern at
} 
you know?' look like? There are many different ways of answering this question but the most straightforward answer will be one that identifies the source or basis of one's knowledge. Genuine knowledge can't be baseless or have no source and that is why explaining how one knows is fundamentally a matter of identifying the source or basis of one's knowledge - one's way of knowing. ${ }^{21}$

Take the proposition that there is a barn in front of me. Clearly, there are many different ways in which I can know that this proposition is true. Maybe I know it is true because, even though I can't see it, I can remember that there is a barn in front of me. Or maybe someone told me that there is a barn in front of me. As noted above, however, there is no better explanation of my knowledge than one that appeals to perception. If I can see the barn or see that there is a barn in front of me then nothing further needs to be done to explain my knowledge. The point here is that perceptual explanations of our knowledge have a kind of intrinsic intelligibility or transparency that few other explanations possess. Indeed, such is the power of the perceptual model of knowledge that some have concluded that 'we have knowledge when and only when it is appropriate to speak of perceiving the truth' (Ayers 1991: 126). ${ }^{22}$ This is, no doubt, something of an exaggeration but there is still something right about the idea that perceiving is the paradigmatic explanation of knowing.

\footnotetext{
the bottom of my garden'. 'How do you know?'. 'I was brought up in the Fens'. There are circumstances in which this would be a perfectly appropriate answer but being brought up in the Fens is not a way of knowing that there is a bittern at the bottom of one's garden or knowing anything else for that matter.

${ }^{21}$ It is because genuine knowledge can't be baseless that self-knowledge seems so paradoxical. Those who think that so-called self-knowledge is baseless or groundless often conclude that it isn't really knowledge. My view is that self-knowledge is knowledge but that it isn't baseless. My knowledge that I am in pain, for example, is not based on evidence but it doesn't follow that it is based on nothing. There is a way in which I know that I am in pain: I can feel it. This raises all sorts of question about ways of knowing and selfknowledge that I can't go into here.

${ }^{22}$ Ayers is here describing what he takes to be Locke's view. Kant's conception of knowledge as requiring both intuitions and concepts is also relevant here since sensible intuitions are perceptions.
} 
If perceiving is that paradigmatic explanation of knowing then this tells us something important about the concept of perception. ${ }^{23}$ It tells us that it is built into this concept that perception is, at least potentially, a route to knowledge. Someone who doesn't understand this is someone who doesn't fully understand what perceiving is. But the explanatory link between perceiving and knowing also reveals something important about the nature of knowledge or the concept of knowledge. It reveals that knowledge is the kind of state that one can get into by perceiving. We understand what knowledge is by understanding how it comes about and perception is a key source of knowledge. It is in this sense that our fundamental understanding of knowledge is as what is yielded by perception in certain circumstances. ${ }^{24}$ This is not a reductive account of knowledge, since the concept of perception isn't more basic than the concept of knowledge, but it is a functional account, one that explicates knowledge in relation to its inputs. ${ }^{25}$ The guiding intuition here is that one gets a grip on the kind of state that knowing is by getting a grip on how one gets into that state. Perceiving is of central importance in this connection because someone perceives that $\mathrm{P}$ is someone who knows that $\mathrm{P}$.

If this is along the right lines then it vindicates Strawson's suggestion that we could not fully elucidate the concept of knowledge without reference to the concept of perception. Indeed, Strawson's formulation is, in the light of the present discussion, something of an understatement. The point is rather that we could not even begin to elucidate the concept of

\footnotetext{
${ }^{23}$ One might wonder why it tells us something about the concept of perception and not about perception. The sensible thing to think is that it tells us something about both. I don't make much of the distinction between perception and the concept of perception or between the concept of knowledge and knowledge itself. For an account that makes much more of this distinction see Kornblith 2002.

${ }^{24}$ The qualification 'in certain circumstances' is due to Snowdon and is needed to deal with, among other things, fake barn scenarios.

${ }^{25}$ See Snowdon 1998 for a somewhat different gloss on idea of a functional account of psychological concepts. Snowdon takes seeing to be a functional concept. If seeing is a functional concept in Snowdon's sense then there will be functional truisms about seeing roughly of the following form: if $\mathrm{S}$ sees $\mathrm{O}$ then $\mathrm{S}$ is capable of G-ing. See Snowdon 1998: 308.
} 
knowledge without reference to the concept of perception. If this makes it difficult to make sense of the idea of knowers who aren't perceivers then so be it. We have also now succeeded in putting some flesh on the bones of the notion of a non-reductive analysis or elucidation of the concept of knowledge. Someone who seeks to explicate the concept of knowledge by talking about ways of knowing is certainly not in the business of dismantling the concept or analysing it in terms of others that are independently intelligible. On the present account, the concepts of knowledge and perception hang together in just the way that Strawson suggests. Neither is more basic than the other.

There are two major worries about my neo-Strawsonian account of knowledge that need to be addressed. The first worry is this: even if we agree that we understand what it is to know by understanding how knowledge comes about why privilege perception among all the different sources of knowledge? It was suggested above that perceptual explanations of our knowledge have a kind of intrinsic intelligibility that few other explanations possess but why think that? In answer to the question 'How do you know there is a barn in front of you?' is the answer 'He told me that there is' in any worse shape than 'I can see it'?. In what sense is the latter explanation any better than one in terms of testimony? As long as we consider knowers in social isolation we might be tempted to privilege perceiving in relation to other ways of knowing but as soon as we think of knowers as belonging to groups or communities of knowers it is not so obvious that perceptual explanations of our knowledge are any more fundamental than testimonial explanations. ${ }^{26}$

The bark of this objection is worse than its bite. Of course it is true that we live in communities of knowers and that testimony rather than perception is the source of much of

\footnotetext{
${ }^{26}$ Making too much of perceptual ways of knowing can also make it difficult to account for a priori knowledge, unless one thinks that it is acceptable to account for this kind of knowledge in terms of some kind of quasi-perceptual rational intuition.
} 
our knowledge. The fact remains, however, that testimonial knowledge is epistemologically not on par with perceptual knowledge. If you tell me that there is a barn in front of me it doesn't follow that there is a barn in front of me. It does follow if I see that there is a barn in front of me. Seeing with one's own eyes is, in this sense, a more basic way of knowing than taking someone else's word for it. Furthermore testimony can transmit knowledge but it can't generate it. ${ }^{27}$ If you tell me that P I can thereby come to know that P only if you already know that P. Perception is important because, very roughly, it explains how anyone knows anything in the first place. Of course, one can also acquire knowledge by inference but inferences need premises and one of the roles of perception is to provide the premises for our inferences. ${ }^{28}$

A more serious concern is this: suppose we agree that perception is a basic source of knowledge. What makes it so? A minimalist is someone who thinks that the connection between knowledge and perception is primitive and cannot be explained any further. On this view, it is just a brute fact that perceiving is the paradigmatic explanation of knowing and that is all there is to it. On the face of it, minimalism is highly implausible. ${ }^{29}$ Surely we want to say that perceiving is a way of knowing because, and only because, there are more general conditions on knowing that $\mathrm{P}$ that one satisfies in virtue of perceiving that $\mathrm{P}$. But these general conditions are just the conditions that traditional analyses of the concept of knowledge have tried to uncover. For example, one might think that knowledge requires reliability and that perception only qualifies as a source of knowledge because it satisfies the reliability condition on knowing. In that case, it might seem to follow that explaining

\footnotetext{
${ }^{27}$ Audi has frequently made this point in his writings. See, for example, Audi 2006. The view that testimony cannot generate knowledge is challenged in Lackey 1999. For some powerful criticisms of Lackey's proposal see Fairley, forthcoming.

${ }_{28}^{28}$ This is, of course, the point of the so-called 'regress argument' for foundationalism.

${ }^{29}$ See Cassam 2007 for further discussion.
} 
the link between perceiving and knowing requires a prior reductive analysis of the concept of knowledge in terms of concepts like reliability.

Fortunately, this doesn't follow. It is true that minimalism is implausible but there is a middle way between minimalism and the idea that a prior reductive analysis of the concept of knowledge is needed to make it intelligible that perceiving is a way of knowing. The point is this: clearly perceiving wouldn't be a way of knowing if it didn't satisfy certain general necessary conditions on knowing, such as the reliability condition. However, the identification of such conditions neither requires a reductive analysis of the concept of knowledge nor implies that any such analysis is possible. Specifically, it does not imply that it is possible to supply non-circular necessary and sufficient conditions for knowing. It only implies the existence of necessary conditions. A non-reductive elucidation of the concept of knowledge can acknowledge the existence of such conditions. Elucidating the concept of knowledge is therefore not just a matter of spelling out the links between the concept of knowledge and the concept of perception. It is also a matter of tracing the complex connections between the concept of knowledge and many other concepts such as

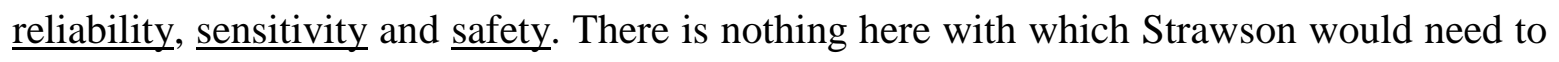
disagree. If anything, it brings out the full force of his connective model of analysis. On the one hand, there are generic conditions on knowing that help us to grasp the link between perceiving and knowing. On the other hand, the fact that perceiving is a paradigmatic way of knowing helps us to flesh out the generic necessary conditions on knowing: we can get a fix on the kind of reliability that knowing requires by reference to the reliability of senseperception. Given that perceiving is a basic way of knowing the reliability that knowing requires had better not be any greater than the reliability of perception. 


\section{Philosophical Methodology.}

Rereading Analysis and Metaphysics roughly a decade and a half after it was first published one is struck by the extent to which it anticipates recent developments in the philosophy of philosophy. The lectures on which the book is based were given at a time when most analytic epistemologists were busy trying, and failing, to come up with Gettierproof reductive analyses of the concept of knowledge. Strawson is rightly dismissive of this way of doing things, even if some of his objections to reductive analysis leave something to be desired. In the last few years, more philosophers have come round to Strawson's view of things. As we have seen, Williamson's criticisms of reductive analysis are very much in the spirit of Strawson's discussion, and the idea that this form of analysis is a dead end has become, if anything, the new orthodoxy. In this respect, Strawson was well ahead of his time.

The biggest challenge facing the new anti-reductionists is to say what the alternative is. Whatever the limitations of the reductive project at least the rules of the game were relatively clear. The minute one talks about 'elucidating' rather than analysing the concept of knowledge it becomes much less clear how we are to proceed or how success is to be measured. Strawson's account of non-reductive analysis in Analysis and Metaphysics raises more questions that it answers but it least the questions it raises are the right ones. What it points to is the possibility of an illuminating account of knowledge that focuses on sources rather than conditions of knowledge. It remains to be seen whether approach can be made to work but it certainly has enough going for it to merit a closer look. 


\section{REFERENCES}

Audi, R. (2002), 'The Sources of Knowledge', in P. Moser (ed.) The Oxford Handbook of Epistemology (Oxford: Oxford University Press).

Audi, R. (2006), 'Testimony, Credulity and Veracity', in J. Lackey and E. Sosa (eds.) The Epistemology of Testimony (Oxford: Oxford University Press).

Austin, J. L. (1979), 'Other Minds', in Philosophical Papers , $3{ }^{\text {rd }}$ Edition (Oxford: Oxford University Press).

Ayers, M. R. (1991), Locke, volume 1: Epistemology (London: Routledge).

Cassam, Q. (2007), 'Ways of Knowing', Proceedings of the Aristotelian Society.

Cassam, Q. (forthcoming), 'Can the Concept of Knowledge be Analysed?', in D. Pritchard and

P. Greenough (eds.) Williamson on Knowledge (Oxford: Oxford University Press).

Dretske, F. (1969), Seeing and Knowing (London: Routledge \& Kegan Paul).

Dretske, F. (2000), 'Simple Seeing', in Perception, Knowledge and Belief (Cambridge:

Cambridge University Press).

Fairely, C. (forthcoming), 'Memory, Testimony and the Primacy of Perception'.

Goldman, A. (1992), 'Discrimination and Perceptual Knowledge', in Liaisons: Philosophy

Meets the Cognitive and Social Sciences (Cambridge, Mass.: The MIT Press).

Kornblith, H. (2002), Knowledge and its Place in Nature (Oxford: Oxford University Press).

Lackey, J. (1999), ‘Testimonial Knowledge and Transmission’, Philosophical Quarterly.

Peacocke, C. (2005), ‘Another 'I”: Representing Conscious States, Perception and Others', in

J. Bermúdez (ed.) Thought, Reference, and Experience: Themes from the Philosophy of Gareth Evans. 
Shoemaker, S. (1996), 'Self-knowledge and "inner sense”. Lecture 1: The object perception model', in The First Person Perspective and Other Essays (Cambridge: Cambridge University Press).

Snowdon, P. F. (1998), ‘Strawson on the Concept of Perception', in L. Hahn (ed.) The Philosophy of P. F. Strawson (Chicago and Lasalle: Open Court).

Snowdon, P. F. (2008), 'Foreword' to Strawson 2008.

Strawson, P. F. (1992), Analysis and Metaphysics: An Introduction to Philosophy (Oxford:

Oxford University Press).

Strawson, P. F. (1995), 'My Philosophy', in P. Sen and R. Verma (eds.) The Philosophy of P.

F. Strawson (New Delhi: Indian Council of Philosophical Research).

Strawson, P. F. (2008), 'Causation in Perception', in Freedom and Resentment and Other

Essays (London: Routledge).

Unger, P. (1975), Ignorance: A Case for Scepticism (Oxford; Clarendon Press).

Williamson, T. (2000), Knowledge and its Limits (Oxford: Oxford University Press). 
